\title{
Diagnosis of vesicoureteral reflux according to the 1999 and 2011 guidelines of the Subcommittee on Urinary Tract Infection of the American Academy of Pediatrics
}

\author{
Marina A. Capone, M.D., Alejandro Balestracci, M.D., Ismael Toledo, M.D., and \\ Sandra M. Martin, M.D. ${ }^{a}$
}

\begin{abstract}
Introduction. In 1999, the American Academy of Pediatrics (AAP) recommended perform a renal ultrasonography and avoiding cystourethrography to all infants between 2 and 24 months of age after their first urinary tract infection (UTI). In 2011, the AAP restricted voiding cystourethrography to children with a pathological ultrasonography, recurrent and/ or atypical infections. Our objective was to compare, in patients with vesicoureteral reflux (VUR) and normal renal ultrasonography, the prevalence of a relevant pathology as if patients had been studied as per the 1999 guidelines (for first UTI) or the 2011 guidelines (for recurrent and/or atypical UTI).
\end{abstract}

Population and methods. We conducted a retrospective analysis of patients with UTI, aged between 2 and 24 months old, seen at our department between January 2010 and August 2014 and who had a normal renal ultrasonography and VUR. A relevant pathology was defined as a finding of grade III VUR or higher and/or pathological renal scintigraphy. Results. Forty-five patients (31 girls) were included and were grouped as if they had been treated as per the 1999 or 2011 guidelines. The prevalence of a relevant pathology among patients studied as per the 1999 guidelines ( 9 out of 24 cases, 3 with atypical UTI) or as per the 2011 guidelines ( 11 out of 21 cases) was similar ( $37.5 \%$ versus $52 \%$, respectively; $p=0.31)$. Six patients $(25 \%)$ with a relevant pathology diagnosed as per the 1999 guidelines would not have been identified in a timely manner with the 2011 version.

a. Nephrology Unit. Hospital General de Niños Pedro de Elizalde, City of Buenos Aires, Argentina

E-mail address:

Marina Andrea Capone, M.D.: marcapone77@ yahoo.com.ar

Funding:

None.

Conflict of interest:

None.

Received: 06-12-2015 Accepted: 09-23-2015 a condition associated with renal parenchymal damage. ${ }^{1}$ In Argentina, VUR nephropathy is a major cause of chronic renal disease and kidney transplant in pediatrics. ${ }^{2}$

There are different guidelines to detect VUR in children with UTI. ${ }^{3}$ As per the recommendations of the Argentine Society of Pediatrics (Sociedad Argentina de Pediatría, SAP), the American Academy of Pediatrics (AAP) guidelines ${ }^{4}$ are used in our department.

The first AAP guidelines were published in 1999 and a renal and bladder ultrasonography and a voiding cystourethrography (VCUG) were recommended to all infants between 2 and 24 months of age after their first febrile UTI. ${ }^{5}$ Subsequently, the need to systematically study all patients was questioned; as a result, the AAP reviewed the guidelines in 2011 and maintained the recommendation to perform an ultrasonography in all patients but restricted VCUGs to patients with a pathological ultrasonography or recurrent UTIs. ${ }^{6}$ It also recommended a VCUG in patients with atypical UTI, although, surprisingly, it did not provide its definition. ${ }^{6}$

Even though such modification reduced the number of VCUGs performed, there was a concern regarding a potentially delayed or missed VUR diagnosis after first UTI in children with a normal renal ultrasonography. ${ }^{7}$ Based on these considerations, we conducted this study in children with VUR who had a normal renal ultrasonography with the objective to identify the prevalence of relevant renal condition 
as if patients had been studied as per the 1999 guidelines (for first UTI) or the 2011 guidelines (for recurrent and/or atypical UTI).

\section{POPULATION, MATERIAL AND METHODS Patients}

Retrospective study conducted at the Nephrology Unit of Hospital General de Niños Pedro de Elizalde. Medical records of all patients with UTI seen at our unit between January 2010 and August 2014 were reviewed. Febrile infants aged between 2 and 24 months old with a first UTI, normal bladder and renal ultrasonography, and VUR diagnosed by VCUG were included. Patients with a genetic syndrome or another disease associated to urinary tract conditions and those with previously known immunodeficiencies were excluded.

\section{Methods}

The following variables were recorded: sex, age at the time of visit and number of UTIs, age at the time of UTIs, ultrasonography findings, VUR grade, and renal scintigraphy results. To establish whether the first UTI was atypical, the following was recorded: if the patient had had sepsis, oligoanuria, increased creatinine level, abdominal or bladder mass, together with the etiologic agent and treatment response.

Until the publication of the 2011 guidelines, all patients had been studied after the first UTI. As of 2011, the decision to study them according to either the 1999 or the 2011 guidelines depended on the treating physician's discretion. Patients with atypical UTI were all studied after the first UTI. Age at the time of VUR diagnosis and proportion of relevant pathologys among studied patients as per the 1999 or 2011 guidelines were established. All imaging studies were performed by specialized physicians from our hospital.

Operational definitions:

- Febrile UTI: UTI associated with axillary temperature $\geq 38^{\circ} \mathrm{C}$, as verified by a physician or as referred by the mother, positive urine culture $\left(>10^{5}\right.$ units forming colony per $\mathrm{mL}$ in midstream urine sample collection, single microorganism), together with an inflammatory response ( $>10$ leukocytes per field and/or pyocyte presence). Counts of $10^{4}$ units forming colony per $\mathrm{mL}$ in urine samples obtained by bladder catheterization were also considered significant. ${ }^{4}$

- Normal bladder and renal ultrasonography: both kidneys with a normal size, shape and echotexture, no hydronephrosis, and normal bladder. $^{8}$

- VUR: retrograde flow of urine from the urinary bladder into the ureter, as diagnosed by VCUG and classified into five grades as per the International Classification of VUR. ${ }^{9}$

- Pathological dimercaptosuccinic acid (DMSA) renal scintigraphy: presence of scarring (focal areas of reduced uptake) or differential renal function higher than $10 \%$ between both kidneys, after at least 6 months from the most recent UTI. ${ }^{8,10}$

- Clinically relevant pathology: grade III VUR or higher and/or pathological renal scintigraphy. ${ }^{8,10}$

- Atypical UTI: the AAP provide no definition of atypical UTI, so we adopted the definition established in the National Institute for Health and Clinical Excellence (NICE) guidelines, that define atypical UTI as UTI concurrent with sepsis, oligoanuria, abdominal or bladder mass, increased creatinine level, failure to respond to treatment within 48 hours and/or infection with non-Escherichia coli organisms. ${ }^{11}$

Ethical considerations: The study was approved by the Ethics Committee and the Research Committee of our hospital.

\section{Statistical analysis}

Considering that the 1999 guidelines ensured VUR diagnosis after the first UTI in all patients and that the 2011 version recommends not performing a VCUG if ultrasonography is normal (a finding observed in approximately 33\% of cases), ${ }^{12}$ we inferred that the ability to diagnose VUR after first the UTI decreased to $67 \%$. With a power of $80 \%$ and a $95 \%$ confidence level, 21 patients per group (studied after first UTI versus after recurrent UTI) would be necessary to evidence a difference in proportions.

Patients were classified as if they had been studied as per the 1999 or 2011 guidelines. ${ }^{5,6}$ Clinical and demographic characteristics and imaging findings were descriptively analyzed. Continuous variables did not have a normal distribution (Shapiro-Wilk's test), so they were expressed as a median (range), while categorical data were expressed as an absolute figures and percentage. Comparisons between groups were done using the Wilcoxon test, the $\chi^{2}$ test or Fisher's exact test, as applicable. The Statistix software, version 7 (IBM version; Analytical Software, Tallahassee, FL) was used, and a $p<0.05$ (two-tailed) was considered significant. 


\section{RESULTS}

The medical records of 489 patients with UTI seen at our Unit between January 2010 and August 2014 were reviewed. Figure 1 shows the patient screening procedure. The study group was made up of 45 patients ( 31 girls). Median age at the time of first UTI diagnosis was 3.9 months old. Six patients had their first UTI after they were 1 year old, three had atypical UTI (two concurrent with sepsis, one caused by Klebsiella pneumoniae). Median age at the time of VUR diagnosis was 12.9 months old (2-48). Grade III-IV VUR was observed in $40 \%$ of patients; and $40 \%$ of cases had bilateral VUR. Renal scintigraphy was done in 34 patients; 10 showed pathological findings.

Patients were then divided into two groups, as if they had been studied as per the 1999 guidelines $(n=24)$ or the 2011 guidelines $(n=21)$. It is worth noting that the three cases of atypical UTI were in the group assessed before the publication of the 2011 guidelines. On the contrary, in the group studied as per the present guidelines, no patient had atypical UTI, so recurrence of UTI was the cause of study in all cases. In the group studied as per the 1999 guidelines, the first UTI occurred at 3.9 months old (2-18) and VUR was diagnosed at 6.9 months old (2-21.9). In the other group, the first UTI occurred at a similar age (4.9 months old [2-24]; $p=0.54)$; recurrence occurred at 10.5 months old (3.9-24), and VUR was diagnosed at a significantly older age (18.8 months old [6.9-48]; $p=0.0002$ ). In a child who had two UTIs (at 2 and 18 months old), VCUG was requested after the latest episode but it was performed at 4 years old, with a delayed diagnosis of grade III VUR. Given that this case overestimates age at diagnosis of VUR in the recurrent UTI group, we assessed whether including it had an influence on the difference in age at diagnosis of VUR between study groups. To this end, we re-estimated age at diagnosis in the recurrent UTI group after excluding this case and observed that VUR diagnosis (15 months old [6.925.9]) would have also occurred at a significantly older age $(p=0.004)$ than in the first UTI group. As expected, female sex predominated in the recurrent UTI group (female/male ratio 6 versus $1.1 ; p=0.02)$.

In the group of patients studied as per the 1999 guidelines, 9 patients (37.5\%) with clinically relevant pathologies were identified. Three of them had atypical UTI, so according to the 2011 guidelines, 6 patients $(25 \%)$ with a significant pathology would not have been identified in a timely manner. In addition, among patients studied as per the 2011 guidelines, 11 (52\%) were identified as having a relevant pathology. No significant differences $(p=0.31)$ were observed in the proportion of relevant pathologies between both groups. Table 1 shows imaging study findings from both groups in detail.

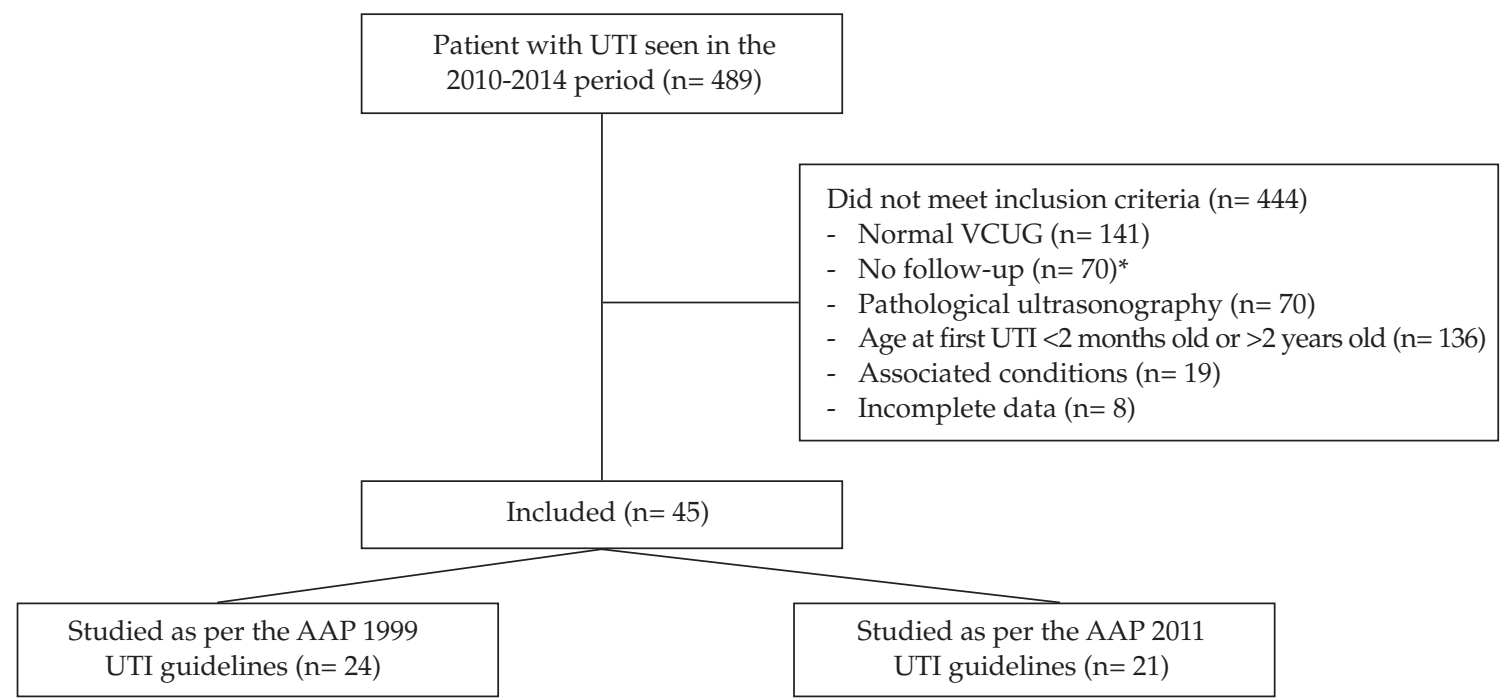

UTI: urinary tract infection; VCUG: voiding cystourethrography; AAP: American Academy of Pediatrics.

* After at least 9 months with no additional visits. 


\section{DISCUSSION}

In this study, children who had a normal renal ultrasonography and VUR were assessed, and the prevalence of a relevant pathology identified with both guideline versions was determined. In the group assessed as per the 1999 guidelines, 9 $(37.5 \%)$ out of 24 patients -three of whom had atypical UTI- were identified as having a relevant pathology. If the 2011 guidelines had been used, 6 patients $(25 \%)$ would have been exposed to a delayed or potentially missed diagnosis of a significant condition based on the fact that in the case of typical UTI with normal ultrasonography it is recommended that VCUG should be delayed. Naturally, delaying VCUG until recurrence also resulted in a significantly older age at the time of VUR diagnosis.

The study plan to be implemented in children with UTI is controversial. The 1999 AAP guidelines were modified based on the following: the benefit of routine antibiotic prophylaxis was questioned, VUR was recognized as not being the only cause of kidney damage, patients who developed a chronic disease tended to have a congenital structural condition, and the high costs associated with studying all patients systematically., ${ }^{3,13-16}$ The more selective approach proposed in 2011 reduced the number of negative VCUGs, ${ }^{6}$ but also generated concern in relation to the potential delay in the diagnosis of a relevant pathology, especially because the renal ultrasonography is a method with low sensitivity and specificity to detect VUR. ${ }^{8,17,18}$ In support of these observations, K. D. Suson and R. Mathews observed that $62 \%$ of patients aged between 2 and 24 months old with normal ultrasonography after the first UTI -without considering if it was an atypical UTI- had grade
III VUR or higher, and that $17 \%$ also had renal scarring. ${ }^{7}$ In our series, a significant pathology after the first UTI was detected in more than one third of cases $(37.5 \%)$, which allowed to identify in advance a group of patients who could receive a therapeutic intervention. Among patients with recurrent UTI, VUR was diagnosed at a significantly older age, and the prevalence of VUR was higher (52\%), but no statistical difference was observed compared to the first group. Although it is unknown whether such delay may have had a clinical impact, there are studies that show that the incidence of scarring is twice as high after a second febrile UTI, so it is important to prevent recurrence among children with VUR. ${ }^{19}$ Although several studies have failed to observe benefits from antibiotic prophylaxis in the prevention of recurrent UTIs, ${ }^{20-22}$ over the past years there is an increasing body of evidence in favor of its prescription. ${ }^{23}$ Brandström et al. demonstrated that chemoprophylaxis significantly reduced the rate of UTI and scarring in girls with grade III-IV VUR. ${ }^{24}$ A recent rigorous clinical trial also demonstrated a $50 \%$ reduction in the risk of recurrence, especially among patients with grade III-IV VUR. ${ }^{25}$

Although such benefit was not accompanied by a lower incidence of new scars, it is worth mentioning that neither the above mentioned study nor most of other studies were designed to assess such outcome. ${ }^{26}$ It has been estimated that a sample of 8000 patients would be needed to assess the effect of antibiotic prophylaxis on the development of scars with an adequate power. ${ }^{27}$

To reinforce such findings, a meta-analysis also revealed that antibiotic prophylaxis significantly reduced the risk of UTI recurrence in children with VUR. ${ }^{28}$ In addition, it has also been documented that anti-reflux surgery reduces

TABLE 1. Findings of imaging studies performed in 45 children with vesicoureteral reflux as if they had been studied as per the 1999 or 2011 guidelines of the Subcommittee on Urinary Tract Infection of the American Academy of Pediatrics

\begin{tabular}{lccc}
\hline Finding & $\begin{array}{c}\text { Studied as per the } \\
\mathbf{1 9 9 9} \text { guidelines } \mathbf{( n = 2 4 )}\end{array}$ & $\begin{array}{c}\text { Studied as per the } \\
\mathbf{2 0 1 1} \text { guidelines (n= 21) }\end{array}$ & $p$ value \\
\hline Grade I VUR & 3 & 4 & 0.68 \\
Grade II VUR & 13 & 7 & 0.16 \\
Grade III VUR & 5 & 7 & 0.5 \\
Grade IV VUR & 3 & 3 & 1 \\
Pathological renal scintigraphy & $4^{*}$ & $6^{\#}$ & 0.27 \\
Significant condition & $9(37.5 \%)$ & $11(52 \%)$ & 0.31 \\
\hline
\end{tabular}

VUR: vesicoureteral reflux.

Significant condition: grade III VUR or higher and/or pathological renal scintigraphy.

* Done in 19 patients: positive findings in three cases of grade III VUR or higher, and one case of grade II VUR.

\# Done in 15 patients: positive findings in five cases of grade III VUR or higher, and one case of grade II VUR. 
that number of UTI, especially in children with grade III-IV VUR. ${ }^{29}$

A timely VUR diagnosis implies other benefits, such as an increased suspicion of new infections where there is a febrile course, thus favoring diagnosis and an early antibiotic therapy. One study demonstrated that a delay of more than 48 hours in antibiotic therapy initiation increases the risk of developing scars by more than $50 \%$ in more than half of cases. ${ }^{6}$ In young children, an early treatment may also prevent sepsis. ${ }^{30}$ In addition, it is worth noting that, although the role of VUR as a determinant of chronic kidney disease is probably over-rated because most of these patients have associated congenital kidney dysplasia, renal scarring may cause arterial hypertension and proteinuria, which require long-term treatment and follow-up. ${ }^{15}$

Other aspects should also be considered when managing children with UTI. First of all, since UTI symptoms in young children are non-specific, ${ }^{6}$ some infections may go undiagnosed, which results in a mistaken categorization of patients to guide the study plan based on the number of infections. Secondly, when implementing these guidelines, the setting is also important, especially when considering the possibility of making periodic controls. ${ }^{31}$ In a study conducted at our hospital, it was observed that $33 \%$ of patients seen at the pediatric emergency department had problems to obtain an appointment with their pediatrician or at a primary care facility, while $8 \%$ did not have a primary care physician at all, which raised doubts regarding an adequate follow-up in many of our patients. ${ }^{32}$ Such healthcare scenario may be a factor that increases even more the risk of a delayed or missed VUR diagnosis, which may occur when postponing a VCUG until recurrence. Actually, one of our patients with recurrent UTI and diagnosed with grade III VUR put off the VCUG for more than two years. What is even more concerning is that $21 \%$ of patients seen due to a UTI between 2 and 24 months of age who had no other associated condition did not return to our department with the results of the VCUG, although it had been duly ordered (Figure 1).

A more selective approach, as proposed by other scientific societies, including the SAP, 33,34 may be a better choice: performing a VCUG in all infants younger than one year old; however, it is necessary to further establish to what extent it helps to correct this problem.

Our study has certain limitations worth being mentioned here. On the one hand, this study was conducted a Nephrology Service and the prevalence of relevant pathologys may have been magnified. However, since most patients with UTI seen at the hospital are referred to our unit to complete their assessment and given that patients with known urinary tract diseases were excluded, the distribution of VUR grades was similar to that observed by other authors. ${ }^{35}$ On the other hand, the fact that no patient from the group assessed after the publication of the 2011 guidelines was studied due to atypical UTI may reflect an inadequate identification of this condition, therefore delaying its referral to be studied.

\section{CONCLUSION}

The percentage of clinically relevant pathologies identified in children with VUR and normal renal ultrasonography was similar with both guideline versions. However, with the implementation of the present guidelines, one in four patients would have been exposed to a delayed or potentially missed diagnosis of a significant condition if the assessment would have been completed after waiting for recurrence.

\section{REFERENCES}

1. Westwood ME, Whiting PF, Cooper J, Watt IS, et al. Further investigation of confirmed urinary tract infection (UTI) in children under five years: a systematic review. BMC Pediatr 2005;5(1):2.

2. Grimoldi IA, Briones LM, Ferraris JR, Rodríguez Rilo L, et al. Enfermedad renal crónica, diálisis y trasplante. Estudio multicéntrico: 1996-2003. Arch Argent Pediatr 2008;106(6):552-9.

3. La Scola C, De Mutiis C, Hewitt IK, Puccio G, et al. Different guidelines for imaging after first UTI in febrile infants: yield, cost, and radiation. Pediatrics 2013;131(3):e665-71.

4. Grimoldi IA, Amore AI. Infección urinaria. In: Ferraris JR, Briones Orfila L, eds. Nefrología Pediátrica. 2a ed. Buenos Aires: Sociedad Argentina de Pediatría;2008. Pages407-23.

5. Downs SM. Technical report: urinary tract infections in febrile infants and young children. The Urinary Tract Subcommittee of the American Academy of Pediatrics Committee on Quality Improvement. Pediatrics 1999;103(4):e54.

6. Subcommittee on Urinary Tract Infection, Steering Committee on Quality Improvement and Management. Urinary tract infection: clinical practice guideline for the diagnosis and management of the initial UTI in febrile infants and children 2 to 24 months. Pediatrics 2011;128(3):595-610.

7. Suson KD, Mathews R. Evaluation of children with urinary tract infection--impact of the 2011 AAP guidelines on the diagnosis of vesicoureteral reflux using a historical series. J Pediatr Urol 2014;10(1):182-5.

8. Massanyi EZ, Preece J, Gupta A, Lin SM, et al. Utility of screening ultrasound after first febrile UTI among patients with clinically significant vesicoureteral reflux. Urology 2013;82(4):905-9. 
9. Lebowitz RL, Olbing H, Parkkulainen KV, Smellie JM, et al. International system of radiographic grading of vesicoureteric reflux. International Reflux Study in Children. Pediatr Radiol 1985;15(2):105-9.

10. Patel K, Charron M, Hoberman A, Brown ML, et al. Intraand interobserver variability in interpretation of DMSA scans using a set of standardized criteria. Pediatr Radiol 1993;23(7):506-9.

11. National Institute for Health and Clinical Excellence. Urinary tract infection in children: diagnosis, treatment and long-term management. London, 2007. [Accessed on: September 23, 2015]. Available at: http://guidance.nice. org.uk/CG054.

12. Lee MD, Lin CC, Huang FY, Tsai TC, et al. Screening young children with a first febrile urinary tract infection for highgrade vesicoureteral reflux with renal ultrasound scanning and technetium-99m-labeled dimercaptosuccinic acid scanning. J Pediatr 2009;154(6):797-802.

13. Mattoo TK. Are prophylactic antibiotics indicated after a urinary tract infection? Curr Opin Pediatr 2009;21(2):203-6.

14. Montini G,HewittI. Urinary tract infections: to prophylaxis or not to prophylaxis? Pediatr Nephrol 2009;24(9):1605-9.

15. Cascio S, Chertin B, Yoneda A, Rolle U, et al. Acute renal damage in infants after first urinary tract infection. Pediatr Nephrol 2002;17(7):503-5.

16. ZaffanelloM, Franchini M, Brugnara M, Fanos V.Evaluating kidney damage from vesico-ureteral reflux in children. Saudi J Kidney Dis Transpl 2009;20(1):57-68.

17. Nelson CP, JohnsonEK, Logvinenko T, Chow JS. Ultrasound as a screening test for genitourinary anomalies in children with UTI. Pediatrics 2014;133(3):e394-403.

18. Hoberman A, Charron M, Hickey RW, Baskin M, et al. Imaging studies after a first febrile urinary tract infection in young children. N C Med J 2003;348(3):195-202.

19. Wan J, Skoog SJ, Hulbert WC, Casale AJ, et al. Section on Urology response to new Guidelines for the diagnosis and management of UTI. Pediatrics 2012;129(4):e1051-3.

20. Pennesi M, Travan L, Peratoner L, Bordugo A, et al. Is antibiotic prophylaxis in children with vesicoureteral reflux effective in preventing pyelonephritis and renal scars? A randomized, controlled trial. Pediatrics 2008;121(6):e1489-94.

21. Garin EH, Olavarria F, Garcia Nieto V, Valenciano B, et al. Clinical significance of primary vesicoureteral reflux and urinary antibiotic prophylaxis after acute pyelonephritis: a multicenter, randomized, controlled study. Pediatrics 2006;117(3):626-32.
22. Montini G, Rigon L, Zucchetta P, Fregonese F, et al. Prophylaxis after first febrile urinary tract infection in children? A multicenter, randomized, controlled, non inferiority trial. Pediatrics 2008;122(5):1064-71.

23. Craig JC,SimpsonJM, Williams GJ, Lowe A, et al. Antibiotic prophylaxis and recurrent urinary tract infection in children. N C Med J 2009;361(18):1748-59.

24. Brandström P, Esbjorner E, Herthelius M, Swerkersson S, et al. The Swedish reflux trial in children: III. Urinary tract infection pattern. J Urol 2010;184(1):286-91.

25. RIVUR Trial Investigators. Antimicrobial prophylaxis for children with vesicoureteral reflux. $N$ C Med I 2014;370(25):2367-76.

26. Mattoo TK, Carpenter MA, Moxey-Mims M, Chesney RW, et al. The RIVUR trial: a factual interpretation of our data. Pediatr Nephrol 2015;30(5):707-12.

27. Hoberman A, Chesney RW. Antimicrobial prophylaxis for children with vesicoureteral reflux. N C Med J 2014;371(11):1072-3.

28. Wang HH, Gbadegesin RA, Foreman JW, Nagaraj SK, et al. Efficacy of antibiotic prophylaxis in children with vesicoureteral reflux: systematic review and meta-analysis. J Urol 2015;193(3):963-9.

29. Sung J, Skoog S. Surgical management of vesicoureteral reflux in children. Pediatr Nephrol 2012;27(4):551-61.

30. Bonadio WA, Smith DS, Madagame E, Machi J, et al. Escherichia coli bacteremia in children. A review of 91 cases in 10 years. Am J Dis Child 1991;145(6):671-4.

31. Ruiz E, de Badiola I. Infección urinaria y reflujo vesicoureteral: qué es necesario hacer. Arch Argent Pediatr 2009;107(4):295-7.

32. VinelliNF,MannucciC,LabaNI, del VecchioL,etal.Consultas no urgentes al Departamento de Urgencias de un hospital pediátrico. Arch Argent Pediatr 2011;109(1):8-13.

33. Indian Society of Pediatric Nephrology, Vijayakumar M, Kanitkar M, Nammalwar BR, et al. Revised statement on management of urinary tract infections. Indian Pediatr 2011;48(9):709-17.

34. Alconcher L, Cobeñas C, Tombesi M. Módulo: Infección Urinaria [Curso virtual]. Programa de actualización en Nefrología Pediátrica Nefroped; 2013. Pages1-12.

35. Camacho V, Estorch M, Fraga G, Mena E, et al. DMSA study performed during febrile urinary tract infection: a predictor of patient outcome? Eur J Nucl Med Mol Imaging 2004;31(6):862-6. 